\title{
Quorum Sensing in the Plant Pathogen Erwinia carotovora subsp. carotovora: The Role of $\exp R_{E c c}$
}

\author{
Robert A. Andersson, ${ }^{1}$ Anders R. B. Eriksson, ${ }^{1}$ Riikka Heikinheimo, ${ }^{1}$ Andres Mäe, ${ }^{2}$ Minna Pirhonen, ${ }^{1}$ \\ Viia Kõiv, ${ }^{2}$ Heidi Hyytiäinen, ${ }^{3}$ Anne Tuikkala, ${ }^{3}$ and E. Tapio Palva ${ }^{3}$ \\ ${ }^{1}$ Department of Plant Biology, Uppsala Genetic Center, Swedish University of Agricultural Sciences, Box

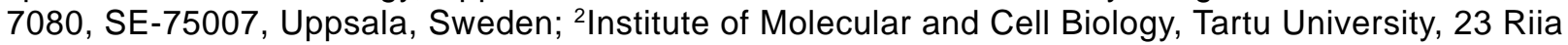 \\ Street, Tartu EE2400, Republic of Estonia; ${ }^{3}$ Department of Biosciences, Division of Genetics, and \\ Institute of Biotechnology, Box 56, FIN-00014 University of Helsinki, Finland \\ Accepted 4 January 2000.
}

The production of the main virulence determinants of the plant pathogen Erwinia carotovora subsp. carotovora, the extracellular cell wall-degrading enzymes, is partly controlled by the diffusible signal molecule $N$-(3-oxohexanoyl)-L-homoserine lactone (OHHL). OHHL is synthesized by the product of the expI/carI gene. Linked to expI we found a gene encoding a putative transcriptional regulator of the LuxR-family. This gene, $\exp R_{E c c}$, is transcribed convergently to the $\operatorname{expI}$ gene and the two open reading frames are partially overlapping. The $\operatorname{ExpR}_{E c c}$ protein showed extensive amino acid sequence similarity to the repressor EsaR from Pantoea stewartii subsp. stewartii (formerly Erwinia stewartii subsp. stewartii) and to the $\operatorname{ExpR}_{E c h}$ protein of Erwinia chrysanthemi. Inactivation of the $E$. carotovora subsp. carotovora $\exp _{E c c}$ gene caused no decrease in virulence or production of virulence determinants in vitro. In contrast, there was a slight increase in the maceration capacity of the mutant strain. The effects of $\operatorname{ExpR}_{E c c}$ were probably mediated by changes in OHHL levels. Inactivation of $\exp R_{E c c}$ resulted in increased OHHL levels during early logarithmic growth. In addition, overexpression of $\exp R_{E c c}$ caused a clear decrease in the production of virulence determinants and part of this effect was likely to be caused by OHHL binding to $\operatorname{ExpR}_{E c c}$. $\operatorname{ExpR}_{E c c}$ did not appear to exhibit transcriptional regulation of expI, but the effect on OHHL was apparently due to other mechanisms.

Corresponding author: E. Tapio Palva; Department of Biosciences, Division of Genetics, Box 56, FIN-00014 University of Helsinki, Finland; Telephone: +358-9-191 59600; Fax +358-9-191 59076; E-mail: Tapio.Palva@helsinki.fi

Present address of Anders R. B. Eriksson: Department of Microbiology, Uppsala Genetic Center, Swedish University of Agricultural Sciences, Box 7025, SE-75007, Uppsala, Sweden.

Present address of Riikka Heikinheimo: National Technology Agency, PO Box 69, FIN-00101 Helsinki, Finland.

Nucleotide and amino acid sequences have been submitted to the EMBL/GenBank/DDJB data bases as accession number X80475.
The soft-rot erwinias, e.g. Erwinia carotovora subsp. carotovora, are considered to be opportunistic plant pathogens that are able to survive in the soil as saprophytes. In conditions favorable to the pathogen they can cause severe damage on the host plants by macerating different plant organs and tissues with multiple extracellular enzymes (Barras et al. 1994; Collmer and Keen 1986; Pérombelon and Kelman 1980). Among these enzymes are cellulases (Cel), pectate lyases (Pel), polygalacturonase (Peh), and proteases (Prt). The production and secretion of these plant cell walldegrading enzymes is of crucial importance for the virulence of E. carotovora subsp. carotovora, as demonstrated, e.g., by isolation of mutants that are affected either in enzyme production (exp, aep, hor, and rex mutants) (Andersson et al. 1999b; Eriksson et al. 1998; Jones et al. 1993; Murata et al. 1991; Pirhonen et al. 1991, 1993; Thomson et al. 1997, 1999) or secretion of these enzymes (out mutants) (Hinton and Salmond 1987; Murata et al. 1990; Pirhonen et al. 1991; Salmond and Reeves 1993).

Production of the extracellular, plant cell wall-degrading enzymes in E. carotovora subsp. carotovora is a tightly controlled process involving both positive (ExpI, ExpA, ExpS, ExpM, Hor, AepA, RexZ, RsmB) and negative (RsmA, HexA, KdgR, RpoS) global regulators (Andersson et al. 1999a, 1999b; Chatterjee et al. 1995; Cui et al. 1995; Eriksson et al. 1998; Harris et al. 1998; Jones et al. 1993; Liu et al. 1993, 1998, 1999; Mukherjee et al. 1996, 1998; Murata et al. 1991; Pirhonen et al. 1991, 1993; Thomson et al. 1997, 1999). We and others have earlier demonstrated that quorum sensing, a term coined by Fuqua et al. (1994), by accumulation of a diffusible signal molecule, $\mathrm{N}$-(3oxohexanoyl)-L-homoserine lactone (OHHL), is a central feature of this regulation in E. carotovora subsp. carotovora (Jones et al. 1993; Pirhonen et al. 1993). Expression of the virulence genes encoding plant cell wall-degrading enzymes is only activated when a sufficient amount of the signal molecule has accumulated. The synthesis of OHHL is directed by the expI/carI gene (Jones et al. 1993; Pirhonen et al. 1991, 1993; Swift et al. 1993) and avirulent E. carotovora subsp. carotovora expI/carI mutants have been shown to lack this diffusible signal molecule (Jones et al. 1993; 
McGowan et al. 1995; Pirhonen et al. 1993). Several related cellular communication systems based on diffusible chemical signals, mainly $\mathrm{N}$-acyl-homoserine lactones (HSL), have been described (for reviews see Fuqua et al. 1994, 1996; Salmond et al. 1995). The paradigm of these systems is the regulation of bioluminescence in the marine bacterium Photobacterium (Vibrio) fischeri (Kaplan and Greenberg 1985). Expression of the structural genes (luxCDABEG) required for light production is dependent on luxI-directed synthesis of the same autoinducer as in E. carotovora subsp. carotovora (OHHL). Accumulation of this autoinducer in the growth medium results in complex formation with the lux gene-specific, DNA-binding protein LuxR. The LuxRautoinducer complex activates expression of the luxICDA$B E G$ operon, creating a positive feedback loop that results in both enhanced production of autoinducer and light emission. Hence, $P$. fischeri is able to sense its own cell density and light is produced only when high enough cell density is reached (for review see Meighen 1991).

The LuxR protein of $P$. fischeri was the first autoinducer-responsive transcriptional activator described. It has been genetically dissected with point mutations and deletions (Choi and Greenberg 1991, 1992a, 1992b; Hanzelka and Greenberg 1995; Shadel et al. 1990; Slock et al. 1990). This analysis has suggested a modular structure for this regulator. The $\mathrm{N}$-terminal part contains the autoinducer-binding domain (Hanzelka and Greenberg 1995) and the C-terminal half the DNA-binding domain (Choi and Greenberg 1992a). These two binding domains appear to be the most conserved areas in the LuxR family of proteins, which now consists of a large number of wellcharacterized transcriptional regulators (for review see Fuqua et al. 1994; Swift et al. 1996). Three LuxR homologues have been characterized in plant-pathogenic bacteria, CarR in E. carotovora subsp. carotovora (McGowan et al. 1995), EsaR in Pantoea stewartii subsp. stewartii (formerly named Erwinia stewartii subsp. stewartii) (von Bodman and Farrand 1995; von Bodman et al. 1998), and ExpR $_{\text {Ech }}$ in Erwinia chrysanthemi (Nasser et al. 1998). CarR is an OHHL-dependent positive regulator of genes involved in the synthesis of the antibiotic carbapenem produced by certain E. carotovora subsp. carotovora strains. EsaR seems to act as a negative regulator of extracellular polysaccharide (EPS) production in $P$. stewartii subsp. stewartii, and esaR mutants constitutively produce this major virulence factor (von Bodman et al. 1998). The E. chrysanthemi $\exp R_{E c h}$ mutant shows no clear phenotype, but it has been shown that the $\operatorname{ExpR}_{E c h}$ protein can interact with the regulatory regions of genes encoding Pels in vitro and also with the promoter of the E. chrysanthemi expI gene (Nasser et al. 1998; Reverchon et al. 1998).

The transcriptional regulator(s) that interacts with OHHL and regulates production of extracellular enzymes has not been identified in E. carotovora subsp. carotovora. In this article, we describe a gene, $\exp R_{E c c}$, that is linked to $\operatorname{expI}$ and show that the $\exp R_{E c c}$ gene product is a structural analog of LuxR. Insertion mutants in $\exp R_{E c c}$ were not reduced in virulence and produced increased amounts of OHHL. Overexpression of $\exp R_{E c c}$ was shown to have a negative effect on the production of virulence factors and this seems to be partly due to $\operatorname{ExpR}_{E c c}$ binding of OHHL.

\section{RESULTS}

The $\exp R_{E c c}$ gene is linked to expI and encodes a putative transcriptional regulator of the LuxR family.

Determination of the complete nucleotide sequence of the insert that complemented the expI mutation (Pirhonen et al. 1991, 1993) revealed the presence of another convergently transcribed open reading frame (ORF) downstream of expI (Fig. 1A). This gene, designated $\exp R_{E c c}$, contained a 735-bp ORF preceded by a putative ribosome binding site (GAGG), $11 \mathrm{bp}$ upstream from the postulated translation initiation codon. A putative translation termination codon (TAG) could also be identified. No sequences typical for either Rhodependent or Rho-independent transcription termination could be detected. The $\operatorname{expI}$ and $\exp R_{E c c}$ ORFs were partially overlapping at their $3^{\prime}$ ends (23 bp). The $\exp R_{E c c}$ ORF encodes a polypeptide of 245 amino acids with a calculated molecular mass of 28,540 Da and an estimated pI of 6.21. The size of the $\exp _{E c c}$ gene product was confirmed by overproduction and selective labeling of the $\operatorname{ExpR}_{E c c}$ polypeptide with the phage T7 expression system (Tabor 1990). Overexpression of the $\exp R_{E c c}$ gene resulted in the production of a single protein product with an apparent molecular mass of $27 \mathrm{kDa}$ in sodium dodecyl sulfate-polyacrylamide gel electrophoresis (SDSPAGE) (data not shown), well in agreement with the calculated molecular mass. When protein data bases were searched with the deduced amino acid sequence of the $\operatorname{ExpR}_{E c c}$ protein, it was found to belong to the LuxR family (Devine et al. 1989; Engebrecht and Silverman 1987). The $\operatorname{ExpR}_{E c c}$ and LuxR polypeptides share identical amino acids throughout the whole sequence, showing an overall identity of $23 \%$, with the Cterminal domain of the $\operatorname{ExpR}_{E c c}$ polypeptide (181 to 245) being the most similar to that of the LuxR protein. This region of LuxR has been demonstrated to contain the DNA-binding domain (Choi and Greenberg 1991, 1992a; Slock et al. 1990). However, the highest degree of similarity between $\operatorname{ExpR}_{E c c}$ and other proteins in the data bases was found to LuxR homologues from other plant pathogens, EsaR from $P$. stewartii subsp. stewartii and $\mathrm{ExpR}_{E c h}$ from E. chrysanthemi (Fig. 1B). EsaR has been shown to be involved in regulation of virulence in P. stewartii subsp. stewartii and acts as a repressor of virulence factors (von Bodman and Farrand 1995;

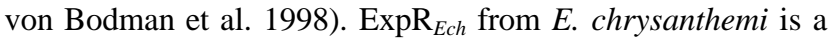
regulatory protein that might be involved as one part of a complex regulatory system that controls quorum sensing (Nasser et al. 1998; Reverchon et al. 1998). $\operatorname{ExpR}_{E c c}$ was shown to share $47 \%$ identity with EsaR and $61 \%$ identity with $\operatorname{ExpR}_{E c h}$ covering both the N-terminal, putative autoinducerbinding domain and the C-terminal, DNA-binding domain (Fig. 1B).

\section{Phenotypic analysis of $\exp R_{E c c}$ mutants of $E$. carotovora subsp. carotovora.}

Based on the results of initial complementation of the $\operatorname{expI}$ mutant (Pirhonen et al. 1993), we knew that $\exp R_{E c c}$ did not suppress the avirulent, enzyme-negative phenotype of $\operatorname{expI}$. To characterize the role of $\operatorname{ExpR}_{E c c}$ in the virulence of E. carotovora subsp. carotovora, two $\exp R_{E c c}$ mutants, SCC5002 and SCC5003, with selectable markers interrupting the $\exp R_{E c c}$ gene at $C l a \mathrm{I}$ and SnaBI sites, respectively, (Fig. 1A) were constructed. Both $\exp R_{E c c}$ mutants appeared to retain the ca- 
pacity to produce autoinducer (OHHL) as well as extracellular plant cell wall-degrading enzymes (Cel, Peh, Pel, and Prt) and SCC5003 was used for further studies. To test whether an $\exp R_{E c c}$ mutation had any effect on virulence of E. carotovora subsp. carotovora, we performed a number of virulence tests. We first compared the virulence of SCC5003 with that of the wild type and found that they had similar virulence in the potato stem assay (data not shown). We then examined the viru- lence of SCC5003 on tobacco by following the in planta growth of the bacteria on in vitro grown tobacco and found that the $\exp R_{E c c}$ mutant and the wild-type strain grew similarly and also caused similar symptoms (data not shown). The maceration capacity of SCC5003 was assessed with a potato tuber assay. The mutant exhibited a somewhat increased capacity to macerate potato tubers, compared with the wild-type strain (Fig. 2A). To elucidate the cause for this enhanced maceration

\section{pTK806-1}

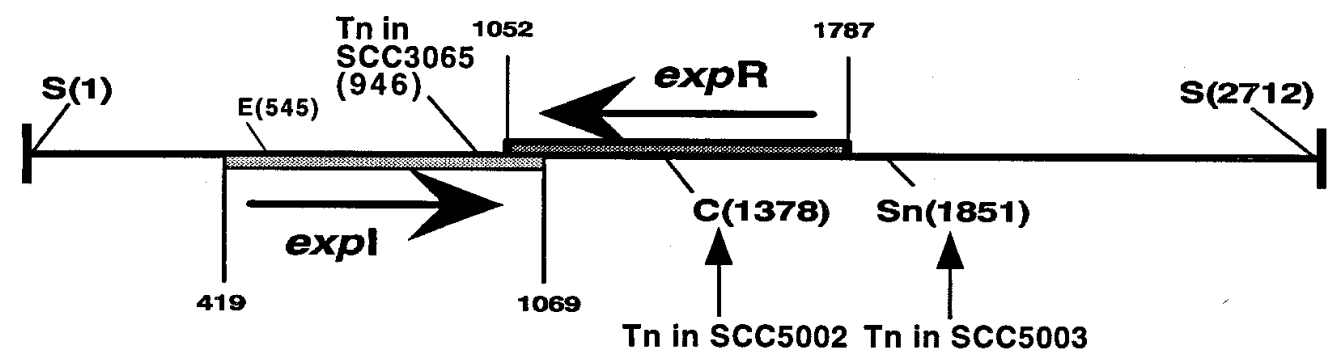

B

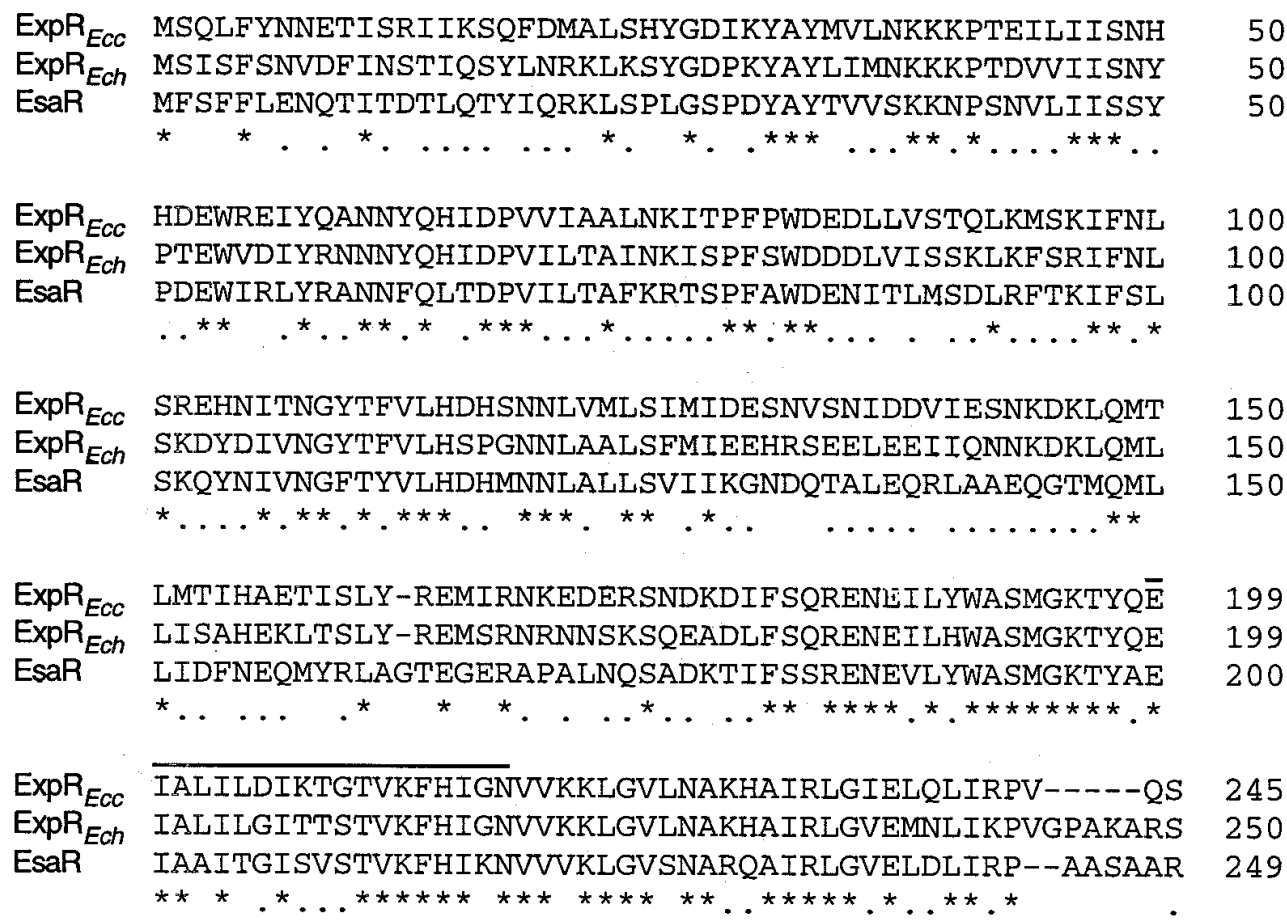

Fig. 1. A, Organization of $\exp R_{E c c}$ and $\exp I$ genes in the genomic 2,712-bp fragment carried by pTK806-1. Open reading frames of both genes are presented as differentially hatched bars with starting and ending base pairs indicated. Direction of transcription is marked by arrows. Restriction enzyme cleavage sites used in construction of the $\exp R_{E c c}$ mutants are indicated; C $=C l a I, S n=S n a \mathrm{BI}$, and E = EcoRI. Terminal Sau3A sites (S) used in the initial cloning (Pirhonen et al. 1991) are shown. Nucleotide numbering as in Pirhonen et al. (1993). Transposon insertions (Tn) positions in SCC3065 (Pirhonen et al. 1991, 1993), SCC5002, and SCC5003 are shown. B, ExpR $E_{E c}$ is similar to other members of the LuxR family. The deduced amino acid sequence of $\operatorname{ExpR}_{E c c}$ (Erwinia carotovora subsp. carotovora) is aligned with that of $\operatorname{ExpR}_{E c h}$ (Erwinia chrysanthemi) (Nasser et al. 1998), and EsaR of Pantoea stewartii subsp. stewartii (von Bodman and Farrand 1995). Identical amino acids are indicated by asterisks; similar amino acids are indicated with dots. Overlined part represents a conserved, possibly DNA-binding, helix-turn-helix motif. 
capacity we characterized the production of extracellular enzymes during the different phases of bacterial growth in vitro. The results from these experiments showed rather similar levels of enzyme activity in SCC3193 and SCC5003. However, we repeatedly observed slightly higher levels of Pel activity,
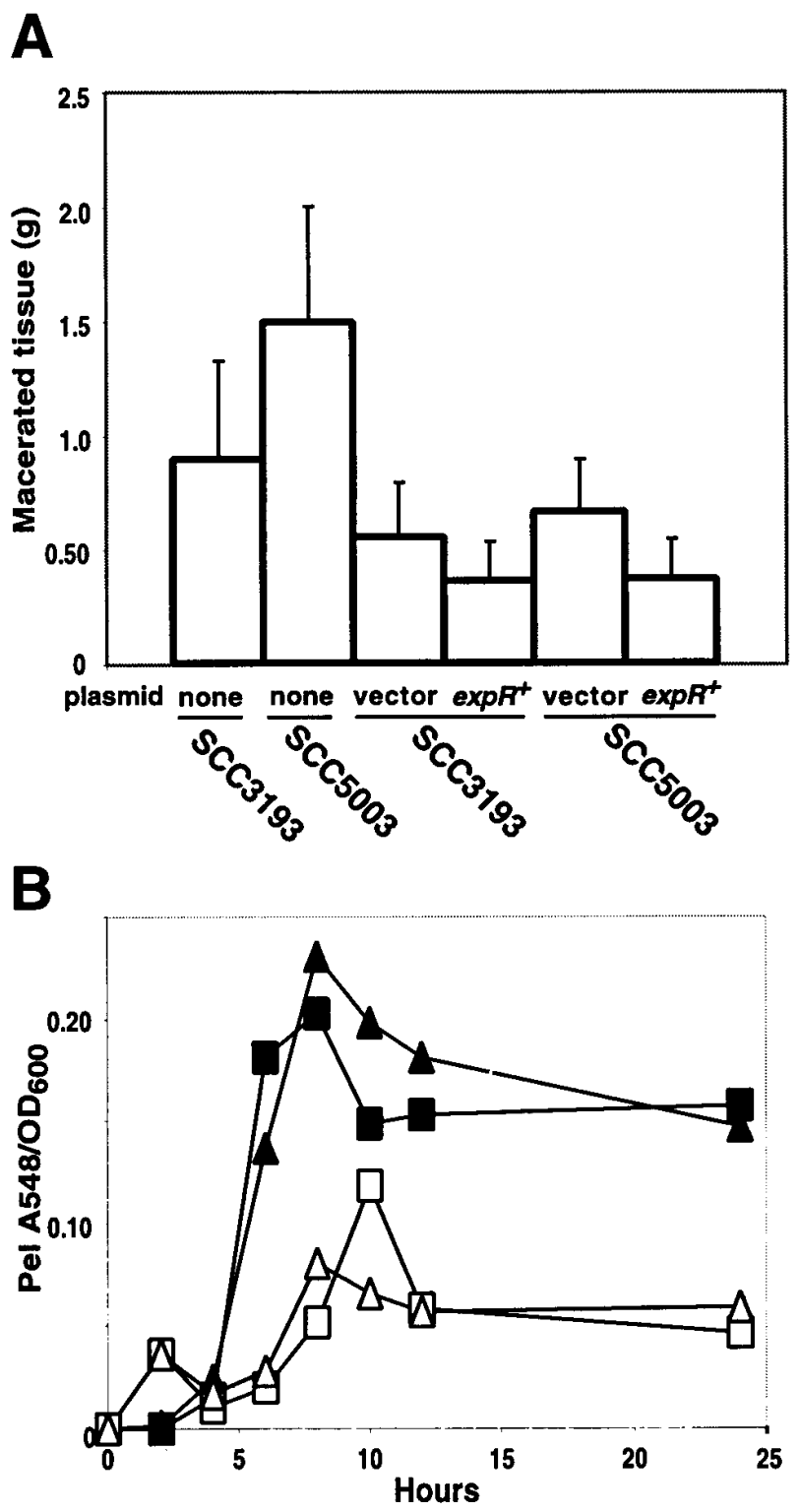

Fig. 2. Effect of $\operatorname{ExpR}_{E c c}$ on tuber maceration and pectate lyase (Pel) production. A, An $\exp _{E c c}$ mutant has increased maceration capacity, and $\exp R_{E c c}$ overexpression causes a significant reduction of maceration capacity. Assay was performed as described (Eriksson et al. 1998); each value is a mean of 16 inoculations with standard deviations. Results were analyzed statistically by means of the Student's $t$ test. $P$ value for the difference between SCC3193 and SCC5003 was 0.00119; between the same strains carrying the vector plasmid (pBluescript II), 0.176. $P$ value for the difference between SCC3193 and SCC5003 carrying the vector plasmid or pSA018 $\left(\operatorname{expR}_{E c c}^{+}\right)$is 0.0107 and 0.000142 , respectively. B, Suppression of Pel production by multiple $\exp R_{E c c}$ copies. SCC3193 (wild type, squares) and SCC5003 (expR $R_{E c c}$ mutant, triangles) carrying a control plasmid, pBluescript II (closed symbols), or pSA018 $\left(\exp R_{E c c}^{+}\right.$open symbols). Samples were taken at time points indicated and Pel activity was measured from culture supernatants. indicating that lack of $\operatorname{ExpR}_{E c c}$ might result in enhanced enzyme production (see Figure $2 \mathrm{~B}$ ). These results suggest that $\exp R_{E c c}$ may not encode a transcriptional activator of virulence genes in E. carotovora subsp. carotovora. In contrast, $\operatorname{ExpR}_{E c c}$ might act as a negative regulator of genes encoding extracellular plant cell wall-degrading enzymes.

\section{Multiple copies of $\exp R_{E c c}$ cause a reduction in the production of virulence factors.}

To assess the possibility that $\operatorname{ExpR}_{E c c}$ negatively regulates extracellular enzyme production we characterized the effect of $\exp R_{E c c}$ overexpression on Pel production. We used the multicopy plasmid pSA018 that carries the $\exp R_{E c c}$ gene under control of its own promoter and another plasmid, pRA801, that allows controlled overexpression of $\exp R_{E c c}$ upon induction by isopropyl $\beta$-D-thiogalactoside (IPTG). These plasmids were transferred separately into SCC3193 and SCC5003 and Pel activity was assayed from culture supernatants. When cells carrying control plasmids were compared, SCC5003 appeared to produce slightly more Pel. Introduction of pSA018 did not significantly affect growth but caused a 50\% reduction in Pel activity (Fig. 2B), and pRA801 caused a similar reduction after induction by IPTG (data not shown). The accumulation of pehA and pelB transcripts was also markedly decreased in cells carrying pRA801 (data not shown). These results indicate that excessive amounts of $\operatorname{ExpR}_{E c c}$ can cause significant reduction of extracellular enzyme production.

To test whether overexpression of $\exp R_{E c c}$ also affected maceration capacity on potato tubers we infected tubers with SCC3193 and SCC5003 carrying either pSA018 or a control plasmid. We found that $\exp R_{E c c}$ overexpression caused a significant decrease in maceration capacity (Fig. 2A). The above results suggested that $\operatorname{ExpR}_{E c c}$ might act as a repressor of the extracellular enzyme encoding genes even though the effect of an $\exp R_{E c c}$ mutation was moderate. To test this hypothesis and to define whether the lack of $\operatorname{ExpR}_{E c c}$ had any effect in the absence of OHHL, we constructed an expIR double mutant strain, SCC6005. We assayed OHHL production in SCC6005 and found that this mutant, as expected, failed to produce OHHL, similarly to the expI mutant strain SCC3065 (see below). We then compared the extracellular enzyme activities of the different strains as well as the accumulation of pehA and pelC transcripts from in vitro grown cultures. The double mutant SCC6005 exhibited reduced accumulation of transcripts (Fig. 3) and production of Peh and Pel (data not shown). In this respect the double mutant was not very different from the expI mutant strain (Pirhonen et al. 1993); however, it appeared to accumulate somewhat increased amounts of the pehA transcript. Assay of virulence on tobacco and potato showed that the double mutant SCC6005 was avirulent on both plant species, similarly to the expI mutant strain (data not shown). Taken together, these results suggest that $\operatorname{ExpR}_{E c c}$ cannot be the main or the sole regulator that mediates the effect of OHHL.

\section{An $\exp R_{E c c}$ mutant has increased levels of OHHL.}

The increased production of extracellular enzymes in $\exp R_{E c c}$ mutants and the repression of enzyme gene expression by multicopy $\exp R_{E c c}$ could be explained by $\exp R_{E c c}$ controlling the level of OHHL. To characterize the effect of $\operatorname{ExpR}_{E c c}$ on OHHL production we compared the levels of OHHL in culture supernatant of the $\exp R_{E c c}$ mutant SCC5003 and the 
wild-type strain SCC3193. The result of this experiment shows that the $\exp R_{E c c}$ mutant produces more OHHL, especially during early exponential growth $\left(2\right.$ to $4 \mathrm{~h} ; \mathrm{OD}_{600} 0.2$ to 0.7 ), while the level of OHHL is more similar between the two strains during late exponential growth and in stationary phase (Fig. 4A). These differences correspond to those seen in enzyme production and consequently the increased enzyme gene expression and maceration capacity of the $\exp R_{E c c}$ mutant strain could indeed be explained by this increase in OHHL. To determine the molecular mechanism of this control we tested whether $\operatorname{ExpR}_{E c c}$ regulated $\operatorname{expI}$ gene expression transcriptionally. We first characterized the effect of $\operatorname{ExpR}_{E c c}$ on transcription of expI with a transcriptional plasmid-borne expI-uidA fusion. This construct was introduced into the wildtype strain SCC3193 and into the $\exp R_{E c c}$ and $\operatorname{expI}$ mutant strains SCC5003 and SCC 3065, respectively. Assay of $\beta$ glucuronidase (GUS) activity did not show any significant differences between these strains (Table 1). These results suggest that $\operatorname{expI}$ is not transcriptionally regulated by $\operatorname{ExpR}_{E c c}$ and that the transcription of $\operatorname{expI}$ does not require OHHL. Northern (RNA) blot analysis was used to investigate whether the accumulation of $\operatorname{expI}$ transcript was affected by an $\exp R_{E c c}$ mutation or by overexpression of $\exp R_{E c c}$. We did not find any significant differences in the level of $\operatorname{expI}$ transcript in an $\exp R_{E c c}$ mutant or in cells carrying pSA018 when compared with wild-type cells (data not shown). Taken together, our results indicate that $\operatorname{ExpR}_{E c c}$ does not act as a direct repressor of expI. Instead, inactivation of $\exp R_{E c c}$ seems to cause increased levels of OHHL by other mechanism(s). One possibility is that ExpR $_{E c c}$ binds OHHL, thus decreasing the levels of free OHHL. According to this hypothesis, $\operatorname{ExpR}_{E c c}$ could affect extracellular enzyme production indirectly by binding OHHL, thus decreasing OHHL availability to other regulators directly involved in OHHL-dependent activation/derepression of virulence genes. To investigate this further, we tested whether addition of synthetic OHHL could relieve the suppression of Pel production when $\exp R_{E c c}$ was overexpressed in the wildtype strain (cf. Figure 2). This experiment showed that the suppression caused by pSA018 was relieved stepwise by addition of $0.1,1$, and $5 \mu \mathrm{g}$ of OHHL per $\mathrm{ml}$ (Fig. 4B), suggesting that the suppression at least partly is caused by $\operatorname{ExpR}_{E c c^{-}}$ mediated binding of OHHL. The increase in Pel activity was up to $86 \%$ in the case of SCC3193 carrying pSA018, compared with a maximum of $29 \%$ in cells carrying a control plasmid. However, the Pel activity did not return to the levels in cells carrying a control plasmid at any OHHL concentration tested. As a control in this experiment we used the $\operatorname{expI~mu-~}$ tant strain SCC3065 (Pirhonen et al. 1991, 1993) that, as expected, was complemented by the addition of OHHL.

\section{DISCUSSION}

The quorum sensing mechanism has been extensively studied in many bacterial species during recent years. This system has been found to regulate several different properties, e.g., light production, plasmid conjugation, and production of virulence factors and antibiotics (reviewed by Fuqua et al. 1994, 1996; Salmond et al. 1995). However, it seems that the function of the system and the organization of the genes involved are far more diverse and complex than first anticipated. In most cases the luxI homologue, which directs the synthesis of one or more homoserine lactone molecule(s), is linked to a $\operatorname{lux} R$ homologue that encodes a response regulator protein. However, there are examples of genes that are not linked, such as traI/traR in Agrobacterium spp. and carI/carR, which regulates antibiotic production in certain E. carotovora subsp. carotovora strains (Salmond et al. 1995). The DNA and autoinducer-binding LuxR homologues have been found to act both positively and negatively, although most proteins appear to act as transcriptional activators. We have previously found a gene, designated $\exp R_{E c c}$, linked to the $\operatorname{expI}$ gene, that directs the synthesis of OHHL (Pirhonen et al. 1993). In this study, we show that $\operatorname{ExpR}_{E c c}$ is structurally similar to LuxR and that the $\operatorname{expI}$ and $\exp R_{E c c}$ ORFs are partially overlapping in their 3' ends and convergently transcribed. Although the similarity between the $\operatorname{ExpR}_{E c c}$ and LuxR proteins was rather moderate (amino acid identity $23 \%$, similarity $31 \%$ ), other regulators of the same family exhibited a higher degree of amino acid identity with $\operatorname{ExpR}_{E c c}$. The most similar proteins were $\operatorname{ExpR}_{E c h}$ (61\% amino acid identity) from E. chrysanthemi (Nasser et al. 1998), EsaR (47\% amino acid identity) of P. stewartii subsp. stewartii (von Bodman and Farrand 1995), and CarR (34\% amino acid identity) controlling carbapenem antibiotic production in certain strains of E. carotovora subsp. carotovora (McGowan et al. 1995). Thus, the regulators characterized in different erwinias (P. stewartii subsp. stewartii was previously named Erwinia stewartii subsp. stewartii) may form a distinct subfamily of LuxR-like proteins sharing a higher degree of amino acid identity with each other than with the other members of the family. The similar amino acids were spread throughout the whole polypeptide; however, regions with high similarity could be located both to the autoinducer-binding

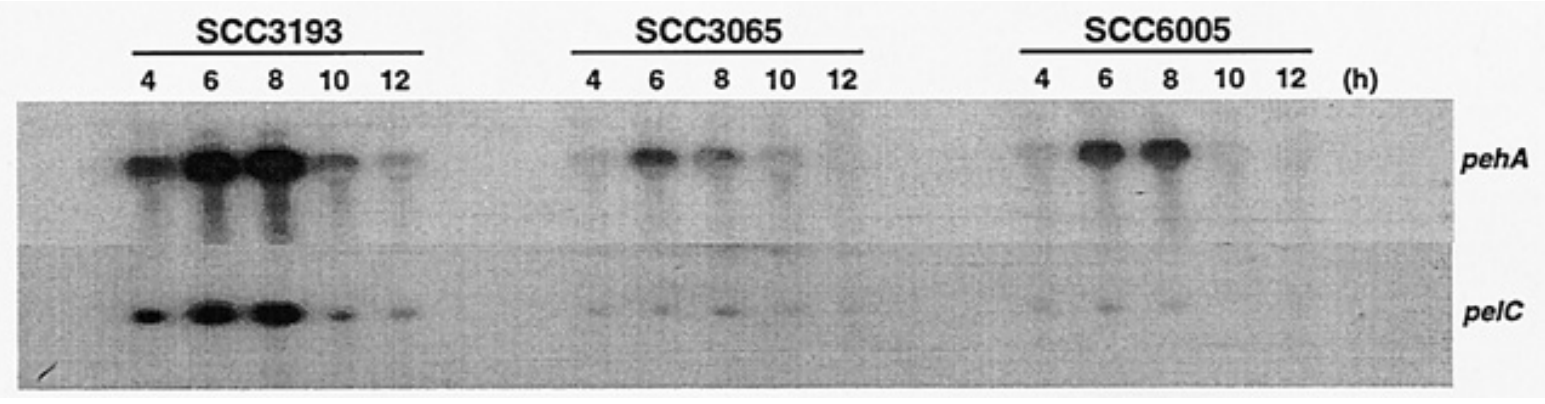

Fig. 3. Phenotype of the expIR double mutant strain SCC6005. Accumulation of transcripts from pehA (Saarilahti et al. 1990) and pelC (Heikinheimo et al. 1995). Cells were grown in L medium with $0.4 \%$ polygalacturonic acid (PGA) and harvested at the time points indicated. SCC3193 is the wild-type strain and SCC3065 is an expI mutant strain (Pirhonen et al. 1991, 1993). Five micrograms of RNA was loaded in each lane. 
region and, especially, to the C-terminal, DNA-binding domain (Choi and Greenberg 1991, 1992a, 1992b; Hanzelka and Greenberg 1995; Shadel et al. 1990; Slock et al. 1990). Consequently, the structural analysis of $\operatorname{ExpR}_{E c c}$ indicates that it may be able to bind autoinducer and that it most likely is a DNA-binding protein.

The linkage between $\operatorname{expI}$ and $\exp R_{E c c}$ and the homology between $\operatorname{ExpR}_{E c c}$ and other LuxR family members suggested

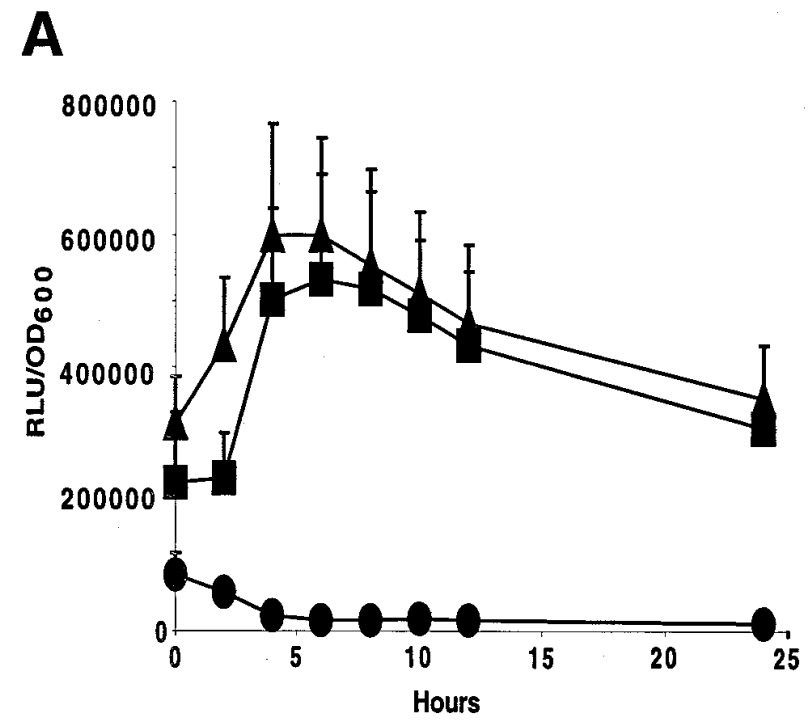

B

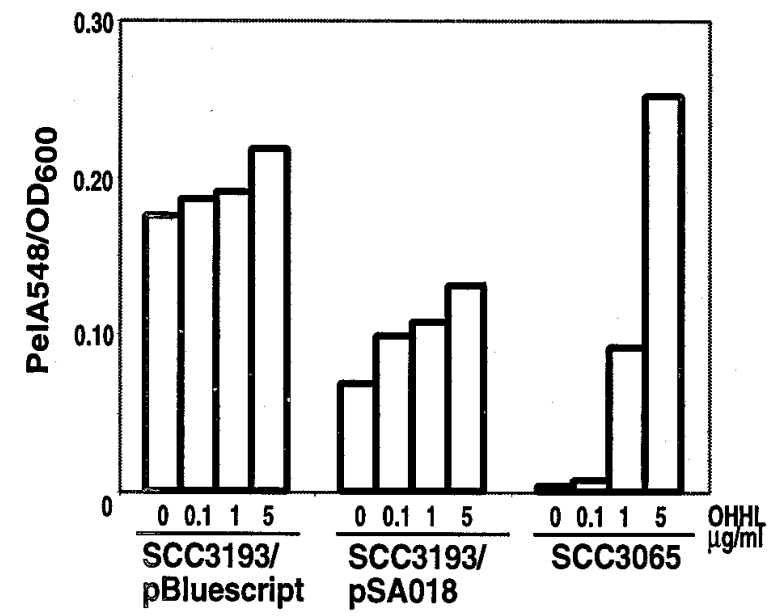

Fig. 4. $\operatorname{ExpR}_{E c c}$ affects the level of Erwinia autoinducer (OHHL). SCC3193 is the wild-type strain and SCC5003 is an $\exp _{E c c}$ mutant strain. A, Levels of OHHL in the supernatant were measured during growth of E. carotovora subsp. carotovora in L medium with $0.4 \%$ polygalacturonic acid (PGA). Squares represent SCC3193, triangles represent SCC5003, and circles represent the expI mutant strain SCC3065, unable to produce OHHL (Pirhonen et al. 1991, 1993), which serves as a negative control. Standard deviation is indicated. B, Effect of OHHL addition on suppression of pectate lyase (Pel) production by multiple $\exp R_{E c c}$ copies (pSA018). Samples were taken from cells grown for $8 \mathrm{~h}$ to an $\mathrm{OD}_{600}$ of about 3. SCC3065 is an expI mutant strain (Pirhonen et al. 1991, 1993), unable to produce OHHL, and serves here as a control. Cells were grown in L medium with $0.4 \%$ PGA. Addition of OHHL in B was done after $3 \mathrm{~h}$ of growth $\left(\mathrm{OD}_{600}\right.$ of about 0.4$)$. Pel activity was measured from culture supernatants. that it, after binding to OHHL, acted as a positive regulator of the virulence genes in E. carotovora subsp. carotovora. Therefore, we were surprised by the finding that the $\exp R_{E c c}$ mutants lacked a clear phenotype in our initial experiments. This suggests that the $\operatorname{ExpR}_{E c c}$ protein may not be a transcriptional activator of the virulence genes; at least $\operatorname{ExpR}_{E c c}$ is not essential for enzyme production and virulence in E. carotovora subsp. carotovora. However, the quorum sensing system might be highly redundant, meaning that other regulator(s) possibly involved cover the lack of $\operatorname{ExpR}_{E c c}$ Therefore, our data do not totally rule out the possibility that $\operatorname{ExpR}$ is a positive regulator under certain conditions.

Our results suggest that $\exp R_{E c c}$ may act negatively on extracellular enzyme production. The evidence for this negative regulatory role of $\exp R_{E c c}$ is as follows: (i) Inactivation of $\exp R_{E c c}$ causes increased levels of OHHL. (ii) Disruption of the $\exp R_{E c c}$ gene leads to a slightly increased Pel production in vitro as well as to somewhat increased macerating capacity of potato tubers. This is consistent with an enhanced production of cell wall-degrading enzymes in planta in the mutant strain, possibly due to the higher levels of OHHL. (iii) Introduction of additional copies of $\exp R_{E c c}$ in trans (pSA018) leads to a $50 \%$ reduction of Pel in the supernatant, presumably at least partly through binding of OHHL. (iv) Overexpression of $\exp R_{E c c}$ from a strong, inducible promoter (pRA801) resulted in complete or almost complete shut-off of virulence gene expression. This was observed both at the transcriptional level (with pehA and pelB target genes) and in the production of the corresponding plant cell wall-degrading enzymes, e.g., Peg and Pel. These data demonstrate that $\exp R_{E c c}$ can, when overexpressed, suppress the production of these virulence determinants. These results are consistent with previous work with the carR gene of the E. carotovora subsp. carotovora strain GS101, encoding a LuxR homologue. CarR acts as a transcriptional activator of antibiotic production in this particular strain. The carR gene is not linked to carl, which directs the synthesis of OHHL in GS101 (McGowan et al. 1995). When carR was introduced on a multicopy plasmid into another strain, SCRI193, that does not produce antibiotics, it was found to reduce the levels of Pel (McGowan et al. 1995), in accordance with our results overexpressing $\exp R_{E c c}$. This effect could, in both cases, be partially remedied by addition of exogenous OHHL. This suggests that high levels of $\operatorname{ExpR}_{E c c}$ (and CarR) drain the pool of OHHL possibly needed by other regulatory protein(s), thereby interfering with their activity, i.e., mimicking the effect of an expI mutation.

It is interesting to note that purified $\operatorname{ExpR}_{E c h}$ from $E$. chrysanthemi binds directly to the promoters of the pel genes,

Table 1. Effect of $\exp R_{E c c}$ on expI expression

\begin{tabular}{llccc}
\hline & & \multicolumn{3}{c}{ GUS activity $^{\mathbf{b}}$} \\
\cline { 3 - 5 } Strain $^{\mathbf{a}}$ & Genotype & $\mathbf{2} \mathbf{~ h}$ & $\mathbf{6 ~ h}$ & $\mathbf{1 0 ~ h}$ \\
\hline SCC3193 & Wild type & 62 & 161 & 348 \\
SCC3065 & expI & 41 & 185 & 413 \\
SCC5003 & $\operatorname{expR}_{\text {Ecc }}$ & 51 & 155 & 343 \\
\hline
\end{tabular}

${ }^{a}$ Expression of a plasmid-borne expI-uidA transcriptional fusion was characterized in the strains indicated.

b $\beta$-Glucuronidase (GUS) activity expressed as nmol product liberated per min per $\mathrm{OD}_{600}$. Cells were grown in $\mathrm{L}$ medium containing $0.4 \%$ polygalacturonic acid (PGA) and harvested at times indicated. Results shown are from a representative experiment. 
among them one of the pel genes from E. carotovora subsp. carotovora (Nasser et al. 1998). The affinity was shown to vary between the various pel genes but the binding could be relieved by addition of autoinducer (OHHL). Interestingly, a protected region has also been found in the promoter region of the E. chrysanthemi expI gene after addition of purified $\operatorname{ExpR}_{E c h}$, but only when OHHL was added (Reverchon et al. 1998). However, an $\exp R_{E c h}$ mutant of E. chrysanthemi did not show any clear phenotype and no significant alteration in Pel production, compared with the wild-type strain.

The most significant effect of an $\exp R_{E c c}$ mutation that we have been able to find so far is the increased level of OHHL during early exponential growth. The finding that there is no difference in the expression of a plasmid-borne transcriptional $\operatorname{expI-uidA}$ fusion between the wild type and the $\exp R_{E c c}$ mutant strain and the fact that the level of $\operatorname{expI}$ transcript was not significantly decreased when $\exp R_{E c c}$ was provided in trans suggest that $\operatorname{ExpR}_{E c c}$ does not regulate $\operatorname{expI}$ transcription. Interestingly, the expression of expI-uidA was unaffected in the expI mutant SCC3065, suggesting that expI is not autoregulated. This is in agreement with Nasser et al. (1998), who found that expI expression in E. chrysanthemi was not altered by the addition of OHHL. Similarly, the expI homologue yenI in Yersinia enterocolitica is not autoregulated and yenI was found to be constitutively expressed throughout the growth cycle (Throup et al. 1995).

Recently, it was shown for the first time that a LuxR homologue, EsaR, in P. stewartii subsp. stewartii functions as a repressor of virulence factor production in this plant pathogen (von Bodman et al. 1998). It has been suggested that the repressor subfamily (EsaR) of LuxR regulators should bind to their target promoters and inhibit transcription in the absence of OHHL (Fuqua et al. 1996; von Bodman et al. 1998). This repression could then be relieved by the action of autoinducer, e.g., by its binding to EsaR. The release of the putative EsaROHHL complex from the promoter would allow activation of the target gene. To test whether a similar mechanism exists in E. carotovora subsp. carotovora, we constructed an expIR double mutant. Although there was a slight increase in pehA expression, this mutant was found to have a phenotype similar to that of the avirulent $\operatorname{expI}$ mutant (Pirhonen et al. 1991, 1993). These results indicate that $\operatorname{ExpR}_{E c c}$-mediated repression of the extracellular enzyme encoding genes in the absence of OHHL cannot be the main reason for the reduced production of virulence determinants in the expI mutant. However, we cannot rule out that $\operatorname{ExpR}_{E c c}$ under certain conditions binds to the promoter regions of the extracellular enzyme encoding genes similarly to the E. chrysanthemi $\operatorname{ExpR}_{E c h}$ protein (Nasser et al. 1998), although in that case it probably plays a minor role in the direct regulation of these genes.

Although our data suggest a negative regulatory role for $\operatorname{ExpR}_{E c c}$, the relatively modest phenotypic effects observed in $\exp R_{E c c}$ mutants indicate that $\operatorname{ExpR}_{E c c}$ is only one of the growing number of regulatory proteins that have been found to modulate virulence gene expression and control virulence in plant pathogenic bacteria (Andersson et al. 1999a, 1999b; Mukherjee et al. 1998; von Bodman and Farrand 1995; von Bodman et al. 1998). This is supported by the finding that a clear phenotype is missing when the $\exp R_{E c h}$ homologue in $E$. chrysanthemi is inactivated (Nasser et al. 1998). It is also possible that the system is redundant, and there are additional
ExpR-like regulators. Consequently, inactivation of one of these would only cause a minor effect in the phenotype. Finally, we cannot exclude the possibility that $\operatorname{ExpR}_{E c c}$ could also control cellular processes other than virulence.

We are currently exploring the interactions between the different regulatory proteins of E. carotovora subsp. carotovora and how this regulatory circuitry is used to control virulence of this plant pathogen. It seems clear that other regulators, directly or indirectly involved in quorum sensing, must exist in E. carotovora subsp. carotovora. Since the isolation of luxI homologues can be done rather easily based on their ability to synthesize homoserine lactone, the lux $R$ homologues linked to the luxI-like genes have been the first ones to be identified and characterized. Therefore, we might so far have missed other important regulators involved in this process.

\section{MATERIAL AND METHODS}

\section{Bacterial strains and plasmids.}

Escherichia coli host strains used for plasmid maintenance and DNA preparation were DH5 $\alpha$ (Hanahan 1983) and XL1blue. The latter was purchased from Stratagene (La Jolla, CA). The E. coli strain C600 was used for selective labeling of the plasmid-encoded proteins (Tabor and Richardsson 1985). The E. carotovora subsp. carotovora wild-type strain SCC3193 (Pirhonen and Palva 1988) and the expI mutant strain SCC3065 (Pirhonen et al. 1991, 1993) have been described. Plasmids pTK806-1 and pTK806-6 have been described by Pirhonen et al. (1993) and plasmids pHP45 $\Omega-\mathrm{Cm}$ and pGP1-2 were described by Fellay et al. (1987) and Tabor (1990), respectively. Plasmid pHV200I has been described by Pearson et al. (1994). Transfer of plasmids was by a standard transformation technique or by electroporation with a Bio-Rad gene pulser (Bio-Rad, Richmond, CA). Alternatively, transduction was used as described previously (Pirhonen et al. 1991) with the transducing bacteriophage T4GT7 (Wilson et al. 1979).

\section{Media, culture conditions, and chemicals.}

E. coli was propagated in L medium (Miller 1972) at $37^{\circ} \mathrm{C}$ and E. carotovora subsp. carotovora at $28^{\circ} \mathrm{C}$. Chloramphenicol $(\mathrm{Cm})$ and kanamycin $(\mathrm{Km})$ were added to media at 25 $\mu \mathrm{g} / \mathrm{ml}$ and ampicillin (Amp) at $150 \mu \mathrm{g} / \mathrm{ml}$ when required. $\mathrm{Cm}$ and $\mathrm{Km}$ were not used during the collection of samples for Northern blots and enzyme assays. Polygalacturonic acid (PGA, P-1879; Sigma, St. Louis, MO) was added to a final concentration of $0.4 \%$ to induce extracellular enzyme production. The sequencing kit was from USB (United States Biochemicals, Cleveland, $\mathrm{OH}$ ); the multiprime DNA labeling kit and radiolabeled compounds were from Amersham International (Buckinghamshire, UK).

\section{Genetic techniques.}

For the generation of $\exp R_{E c c}$ marker-exchange mutants, two constructs carrying the $\exp R_{E c c}$ gene interrupted by a $\mathrm{Cm}$ resistance gene were made by first digesting the $\mathrm{Cm}$-specific, $3.5-\mathrm{kb}$ interposon fragment of plasmid $\mathrm{pHP} 45 \Omega-\mathrm{Cm}$ (Fellay et al. 1987) with EcoRI restriction enzyme followed by isolation of the $\Omega-\mathrm{Cm}$ fragment. This fragment was blunt ended with Klenow and ligated with ClaI (SCC5002) or SnaBI (SCC5003) digested and blunt-ended pTK806-1. The resulting 
two plasmid constructs were named pRK14 and pRK15. For marker exchange, SCC3193/pRK14 and SCC3193/pRK15 were grown overnight on $\mathrm{Cm}$ selection and left standing at room temperature for $48 \mathrm{~h}$. Recombinants were selected on L$\mathrm{Cm}$ plates and true marker exchange mutants were screened for by loss of the vector marker (Amp). These mutants were further characterized by Southern analysis of isolated and digested chromosomal DNA and probed separately with $\exp R_{E c c}$

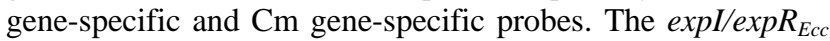
double mutant SCC6005 was constructed with the following strategy: The $\Omega-\mathrm{Cm}$ resistance marker from $\mathrm{pHP} 45 \Omega-\mathrm{Cm}$ (Fellay et al. 1987) was cut out from the plasmid with HindIII. The resulting fragment was blunt ended and inserted into pTK806-1 (Pirhonen et al. 1993) that been restricted with EcoRI/ClaI and blunt ended. This creates a deletion of about 800 bp in pTK806-1 that spans almost the entire expI gene and about $325 \mathrm{bp}$ of $\exp R_{E c c}$ (see Figure 1A). From this construct the fragment containing the $\Omega-\mathrm{Cm}$ gene with remaining flanking parts of the $\exp R_{E c c}$ and $\operatorname{expI}$ genes was cut out with $X b a \mathrm{I}$, blunt ended, and cloned into mini- $\mathrm{Tn} 5 \mathrm{Km} 1$, previously cut with EcoRI/XbaI to delete the $\mathrm{Km}$ resistance gene. The resulting plasmid was mobilized by conjugation from $E$. coli S17-1 $\lambda$ pir into E. carotovora subsp. carotovora SCC3193 as described (de Lorenzo and Timmis 1994). Transconjugants were selected as described (Andersson et al. 1999b). Desired mutations were then confirmed by Southern blot. The expIuidA fusion was constructed as follows: a promoterless $E$. coli uidA gene was amplified by polymerase chain reaction (PCR) and cloned into pBR322. The expI promoter region (353 bp upstream of the ATG in the expI ORF) was amplified by PCR with primers $5^{\prime}$-AACTGAGCTC TATGCTGAAA CAGGCTTGCT TTCTTC-3' and 5'-CCGACAGTAG TGTGAAGCTT ACATCG-3' and cloned in front of uidA. This construct was then confirmed by sequencing. Plasmid pSA018, which contains the $\exp _{E c c}$ gene in pBluescript II, was constructed by amplifying $\exp R_{E c c}$ including the promoter region by PCR with the primers $5^{\prime}$-TTTGGTACCT GATAAATCTC GCTTAATTAG CATT-3' and 5'AAAGAGCTCC TATGACTGAA CCGGTCGGAT A-3' and chromosomal DNA from SCC3193 as a template. The 3' primer used ended at the translational stop codon of $\exp R_{E c c}$. The construct for the controlled $\operatorname{ExpR}_{E c c}$ overproduction was done as follows: two synthetic 33-mer oligonucleotides primers (5'-TCTCCAGGAT CCATGTCGCA GTTATTCTAC AAC- $3^{\prime}$ and 5'-ACAGAAAAGC TTCTATGACT GAACCGGTCG GAT-3') were used to amplify $\exp R_{E c c}$ from the chromosome of SCC3193. The resulting 737-bp PCR product was cloned as a BamHI-HindIII fragment into the corresponding sites of the pQE-30 expression vector (Qiagen, Hilden, Germany) to obtain pRA801. In this vector system, expression is driven from the bacteriophage T5 promoter under control of the lac operator. Plasmid pRA801 was transformed into cells that already harbored the pREP4 plasmid (Qiagen) encoding the LacI repressor protein. All PCRs were performed with the proofreading polymerase Pfu (Stratagene).

DNA manipulation, deletion analysis, and determination of the nucleotide sequence.

Unless otherwise stated, isolation of plasmid DNA or chromosomal DNA, cloning, and gel analysis of plasmid DNA were by established procedures as described in Sam- brook et al. (1989). Unidirectional deletions of pTK806-1 were generated by cleaving plasmids with appropriate restriction enzymes within the multiple cloning site to create $3^{\prime}$ or $5^{\prime}$ overhangs, followed by digestion of the $3^{\prime}$ recessed strand with exonuclease III (Henikoff 1984) with the pBluescript II Exo III/Mung Bean DNA deletion kit (Stratagene). Single-strand DNA was removed with mung bean nuclease and blunt ends were ligated and plasmids transformed into $E$. coli XL1-blue strain. Sequencing was performed on both strands by the Sanger dideoxy-chain termination method (Sanger et al. 1977). Amino acid alignments with deduced amino acid sequences were done according to the Needleman-Wunsch algorithm with the PC/GENE package (Oxford Molecular, Oxford).

\section{Isolation of chromosomal DNA and total RNA, and Southern and Northern blot analyses.}

Chromosomal DNA was isolated essentially as described by Sambrook et al. (1989) and RNA was isolated by the RNeasy kit (Qiagen). For Southern analysis, chromosomal DNA was digested with restriction enzymes and run on an $0.8 \%$ agarose gel. Northern analysis was done essentially as described (Eriksson et al. 1998) with $5 \mu \mathrm{g}$ of total RNA and probes specific for $\exp R_{E c c}, \operatorname{expI}, p e h A, p e l B$, and pelC. A HindIII$H i n d I I I$ interposon fragment from pHP $45 \Omega-C m$ was used as a probe for the $\mathrm{Cm}$ resistance gene. Probe fragments were labeled with ${ }^{32} \mathrm{P}$-dATP by random primer labeling.

\section{Overproduction of $\operatorname{ExpR}_{E c c}$.}

Selective labeling of the $\operatorname{ExpR}_{E c c}$ protein was achieved with the T7 RNA polymerase/promoter system essentially as described by Tabor (1990) from the $\exp R_{E c c}$ gene construct on pTK806-6 (Pirhonen et al. 1993). Labeled proteins were separated by SDS-PAGE and the proteins were visualized by autoradiography of dried gels previously stained with Coomassie brilliant blue. For controlled overexpression of $\exp R_{E c c}$, the E. carotovora subsp. carotovora wild-type strain SCC3193 harboring both pRA801 and pREP4 plasmids was grown overnight in L medium containing Amp, $\mathrm{Km}$, and $2 \%$ of glucose. The overnight culture was diluted 1:50 into fresh medium without glucose, containing the appropriate antibiotics and $0.4 \%$ PGA, grown for $4 \mathrm{~h}$. Expression of $\exp R_{E c c}$ was induced in these mid-logarithmic cultures by addition of IPTG to a final concentration of $2 \mathrm{mM}$. Cultures were grown in the presence of IPTG for $8 \mathrm{~h}$ and samples were collected every second hour.

\section{Assay procedures.}

Extracellular enzyme indicator plates (Cel, Peh, Pel, and Prt) were as in Pirhonen et al. (1993) and Peh and Pel assays as in Pirhonen et al. (1991). OHHL was measured in a bioassay as follows. Ten microliters of supernatant was diluted with $\mathrm{L}$ medium and mixed with $100 \mu \mathrm{l}$ of sensor strain $(E$. coli DH5 $\alpha$ harboring the $\mathrm{pHV}^{200 \mathrm{I}^{-}}$plasmid). Emission of light was measured during a time curve ( 0 to $2 \mathrm{~h}$ ), every $30 \mathrm{~min}$ with the 1420 multilabel counter VICTOR $^{2}$ (Wallac Oy, Turku, Finland). Results were calculated as slopes of relative light units (RLU) and final values were defined as RLU/OD 600 $\left(\mathrm{RLU} \times \mathrm{ml}^{-1} \times 10^{2} / \mathrm{OD}_{600} \times \mathrm{ml}^{-1}\right)$. Experiments with addition of synthetic OHHL were done as follows: cells were grown for $3 \mathrm{~h}\left(\mathrm{OD}_{600}\right.$ about 0.4$)$ in L medium with $0.4 \%$ PGA. At 
this point, OHHL was added to a final concentration of $0.1,1$, or $5 \mu \mathrm{g} / \mathrm{ml}$. Incubation was then continued for $5 \mathrm{~h}$, when samples were taken and Pel activity was assayed from culture supernatants. GUS assays were done according to Wilson (1996).

\section{Virulence assays.}

Maceration of potato tubers (Solanum tuberosum cv. Bintje) was tested as described in Eriksson et al. (1998). Results were analyzed statistically by the Student's $t$ test. A $P$ value below 0.05 indicates significance at the $95 \%$ level whereas a $P$ value below 0.01 indicates significance at the $99 \%$ level. Virulence on plants, Nicotiana tabacum cv. Samsun, was tested by inoculating the plants with $10^{6} \mathrm{CFU}$ and determining the number of viable bacteria as described earlier (Vidal et al. 1998). Assays on potato stems were done as described by McMillan et al. (1993).

\section{ACKNOWLEDGMENTS}

We thank Maj-Britt Karlsson, Gunvor Sandman, Mona Munther, and Annelie Rimmer for skillful technical assistance. Synthetic OHHL was kindly provided by Paul Williams and the plasmid pHV200I by E. P. Greenberg and Kendall Gray. This work was supported by the Swedish Council for Forestry and Agricultural Research. Grants from the Nilsson-Ehle foundation, Oscar and Lili Lamms foundation, P. O. Lundells foundation (Uppsala University), and Stina and Richard Högbergs foundation (SLU) are gratefully acknowledged. E. T. P. is currently supported by the Academy of Finland and Biocentrum Helsinki. E. T. P. and A. M. are also supported by the EU (ERBIC15-CT96-0908).

\section{LITERATURE CITED}

Andersson, R. A., Kõiv, V., Norman-Setterblad, C., and Pirhonen, M. 1999a. Role of RpoS in virulence and stress tolerance of the plant pathogen Erwinia carotovora subsp. carotovora. Microbiology 145: 3547-3556

Andersson, R. A., Palva, E. T., and Pirhonen, M. 1999b. The response regulator ExpM is essential for the virulence of Erwinia carotovora subsp. carotovora and acts negatively on the sigma factor $\operatorname{RpoS}\left(\sigma^{\mathrm{S}}\right)$. Mol. Plant-Microbe Interact. 12:575-584.

Barras, F., van Gijsegem, F., and Chatterjee, A. K. 1994. Extracellular enzymes and pathogenesis of soft-rot Erwinia. Annu. Rev. Phytopathol. 32:201-234.

Chatterjee, A., Cui, Y., Liu, Y., Dumenyo, C. K., and Chatterjee, A. K. 1995. Inactivation of rsmA leads to overproduction of extracellular pectinases, cellulases, and proteases in Erwinia carotovora subsp. carotovora in the absence of the starvation/cell density sensing signal, $N$-(3-oxohexanoyl)-L-homoserine lactone. Appl. Environ. Microbiol. 61:1959-1967.

Choi, S. H., and Greenberg, E. P. 1991. The C-terminal region of the Vibrio fischeri LuxR protein contains an inducer-independent lux gene activating domain. Proc. Natl. Acad. Sci. USA 88:11115-11119.

Choi, S. H., and Greenberg, E. P. 1992a. Genetic dissection of DNA binding and luminescence gene activation by the Vibrio fischeri LuxR protein. J. Bacteriol. 174:4064-4069.

Choi, S. H., and Greenberg, E. P. 1992b. Genetic evidence for multimerization of LuxR, the transcriptional activator of Vibrio fischeri luminescence. Mol. Marine Biol. Biotechnol. 1:408-413.

Collmer, A., and Keen, N. T. 1986. The role of pectic enzymes in plant pathogenesis. Annu. Rev. Phytopathol. 24:383-409.

Cui, Y., Chatterjee, A., Liu, Y., Dumenyo, C. K., and Chatterjee, A. K. 1995. Identification of a global repressor gene, rsmA, of Erwinia carotovora subsp. carotovora that controls extracellular enzymes, $\mathrm{N}$ (3-oxohexanoyl)-L-homoserine lactone, and pathogenicity in softrotting Erwinia spp. J. Bacteriol. 177:5108-5115.

de Lorenzo, V., and Timmis, K. N. 1994. Analysis and construction of stable phenotypes in gram-negative bacteria with Tn5- and Tn10derived minitransposons. Methods Enzymol. 235:386-405.
Devine, J. H., Shadel, G. S., and Balwin, T. O. 1989. Identification of the lux regulon from the Vibrio fischeri strain ATCC7744. Proc. Natl. Acad. Sci. USA 86:5688-5692.

Engebrecht, J., and Silverman, M. 1987. Nucleotide sequence of the regulatory locus controlling expression of bacterial genes for bioluminescence. Nucleic Acids Res. 15:10455-10467.

Eriksson, A. R. B., Andersson, R. A., Pirhonen, M., and Palva, E. T. 1998. Two-component regulators involved in the global control of virulence in Erwinia carotovora subsp. carotovora. Mol. PlantMicrobe Interact. 11:743-752.

Fellay, R., Frey, J., and Krisch, H. 1987. Interposon mutagenesis of soil and water bacteria: A family of DNA fragments designed for in vitro insertional mutagenesis of gram-negative bacteria. Gene 52:147-154.

Fuqua, C., Winans, S. C., and Greenberg, E. P. 1996. Census and consensus in bacterial ecosystems: The LuxR-LuxI family of quorumsensing transcriptional regulators. Annu. Rev. Microbiol. 50:727-751.

Fuqua, W. C., Winans, S. C., and Greenberg, E. P. 1994. Quorum sensing in bacteria: The LuxR-LuxI family of cell density-responsive transcriptional regulators. J. Bacteriol. 176:269-275.

Hanahan, D. 1983. Studies on transformation of Escherichia coli with plasmids. J. Mol. Biol. 166:557-580.

Hanzelka, B. L., and Greenberg, E. P. 1995. Evidence that the Nterminal region of the Vibrio fischeri LuxR protein constitutes an autoinducer-binding domain. J. Bacteriol. 177:815-817.

Harris, S. J., Shih, Y.-L., Bentley, S. D., and Salmond, G. P. C. 1998. The hexA gene of Erwinia carotovora encodes a LysR homologue and regulates motility and the expression of multiple virulence determinants. Mol. Microbiol. 28:705-717.

Heikinheimo, R., Flego, D., Pirhonen, M., Karlsson, M.-B., Eriksson, A., Mäe, A., Kõiv, V., and Palva, E. T. 1995. Characterization of a novel pectate lyase from Erwinia carotovora subsp. carotovora. Mol. Plant-Microbe Interact. 8:207-217.

Henikoff, S. 1984. Unidirectional digestion with exonuclease III creates targeted breakpoints for DNA sequencing. Gene 28:351-359.

Hinton, J. C. D., and Salmond, G. P. C. 1987. Use of Tn phoA to enrich for extracellular enzyme mutants of Erwinia carotovora subspecies carotovora. Mol. Microbiol. 1:381-386.

Jones, S., Yu, B., Bainton, N. J., Birdsall, M., Bycroft, B. W., Chhabra, S. R., Cox, A. J. R., Golby, P., Reeves, P. J., Stephans, S., Winson, M. K., Salmond, G. P. C., Stewart, G. S. A. B., and Williams, P. 1993. The lux autoinducer regulates the production of exoenzyme virulence determinants in Erwinia carotovora and Pseudomonas aeruginosa. EMBO J. 12:2477-2482.

Kaplan, H. B., and Greenberg, E. P. 1985. Diffusion of autoinducer is involved in regulation of the Vibrio fischeri luminescence system. J. Bacteriol. 163:1210-1214.

Liu, Y., Cui, Y., Mukherjee, A., and Chatterjee, A. K. 1998. Characterization of a novel RNA regulator of Erwinia carotovora ssp. carotovora that controls production of extracellular enzymes and secondary metabolites. Mol. Microbiol. 29:219-234.

Liu, Y., Jiang, G., Cui, Y., Mukherjee, A., Ma, W. L., and Chatterjee, A. K. 1999. $k d g R_{E c c}$ negatively regulates genes for pectinases, cellulase, protease, harpin $\operatorname{Ecc}_{\text {, }}$, and a global RNA regulator in Erwinia carotovora subsp. carotovora. J. Bacteriol. 181:2411-2421.

Liu, Y., Murata, H., Chatterjee, A., and Chatterjee, A. K. 1993. Characterization of a novel regulatory gene aepA that controls extracellular enzyme production in the phytopathogenic bacterium Erwinia carotovora subsp. carotovora. Mol. Plant-Microbe Interact. 6:299-308.

McGowan, S., Sebaihia, M., Jones, S., Yu, B., Bainton, N., Chan, P. F., Bycroft, B., Stewart, G. S. A. B., Williams, P., and Salmond, G. P. C. 1995. Carbapenem antibiotic production in Erwinia carotovora is regulated by CarR, a homologue to the LuxR transcriptional activator. Microbiology 141:541-550.

McMillan, G. P., Hedley, D., Fyffe, L., and Pérombelon, M. C. M. 1993. Potato resistance to soft-rot erwinias is related to cell wall pectin esterification. Physiol. Mol. Plant Pathol. 42:279-289.

Meighen, E. A. 1991. Molecular biology of bacterial bioluminescence. Microbiol. Rev. 55:123-142.

Miller, J. H. 1972. Page 466 in: Experiments in Molecular Genetics. Cold Spring Harbor Laboratory, Cold Spring Harbor, NY.

Mukherjee, A., Cui, Y., Liu, Y., Dumenyo, C. K., and Chatterjee, A. K. 1996. Global regulation in Erwinia species by Erwinia carotovora rsmA, a homologue of Escherichia coli csrA: Repression of secondary metabolites, pathogenicity and hypersensitive reaction. Microbiology 
142:427-434

Mukherjee, A., Cui, Y., Ma, W., Liu, Y., Ishihama, A., Eisenstark, A., and Chatterjee, A. K. 1998. RpoS (Sigma-S) controls expression of rsmA, a global regulator of secondary metabolites, harpin, and extracellular proteins in Erwinia carotovora. J. Bacteriol. 180:3629-3634.

Murata, H., Fons, M., Chatterjee, A., Collmer, A., and Chatterjee, A. K. 1990. Characterization of transposon insertion out mutants of $\mathrm{Er}$ winia carotovora subsp. carotovora defective in enzyme export and of a DNA segment that complements out mutations in E. carotovora subsp. carotovora, E. carotovora subsp. atroseptica, and Erwinia chrysanthemi. J. Bacteriol. 172:2970-2978.

Murata, H., McEvoy, J. L., Chatterjee, A., Collmer, A., and Chatterjee, A. K. 1991. Molecular cloning of an aepA gene that activates production of extracellular pectolytic, cellulolytic, and proteolytic enzymes in Erwinia carotovora subsp. carotovora. Mol. Plant-Microbe Interact. 4:239-246.

Nasser, W., Bouillant, M. L., Salmond, G., and Reverchon, S. 1998. Characterization of the Erwinia chrysanthemi expl-expR locus directing the synthesis of two $N$-acyl-homoserine lactone signal molecules. Mol. Microbiol. 29:1391-1405.

Pearson, J. P., Gray, K. M., Passador, L., Tucker, K. D., Eberhard, A., Iglewski, B. H., and Greenberg, E. P. 1994. Structure of the autoinducer required for expression of Pseudomonas aeruginosa virulence genes. Proc. Natl. Acad. Sci. USA 91:197-201.

Pérombelon, M. C. M., and Kelman, A. 1980. Ecology of the soft rot Erwinias. Annu. Rev. Phytopathol. 18:361-387.

Pirhonen, M., Flego, D., Heikinheimo, R., and Palva, E. T. 1993. A small diffusible signal molecule is responsible for the global control of virulence and exoenzyme production in the plant pathogen Erwinia carotovora. EMBO J. 12:2467-2476.

Pirhonen, M., and Palva, E. T. 1988. Occurrence of bacteriophage T4 receptor in Erwinia carotovora. Mol. Gen. Genet. 214:170-172.

Pirhonen, M., Saarilahti, H., Karlsson, M.-B., and Palva, E. T. 1991. Identification of pathogenicity determinants of Erwinia carotovora subsp. carotovora by transposon mutagenesis. Mol. Plant-Microbe Interact. 4:276-283.

Reverchon, S., Bouillant, M. L., Salmond, G., and Nasser, W. 1998. Integration of the quorum-sensing system in the regulatory networks controlling virulence factor synthesis in Erwinia chrysanthemi. Mol. Microbiol. 29:1407-1418.

Saarilahti, H. T., Heino, P., Pakkanen, R., Kalkkinen, N., Palva, I., and Palva, E. T. 1990. Structural analysis of the pehA gene and characterization of its protein product, endopolygalacturonase, of Erwinia carotovora subspecies carotovora. Mol. Microbiol. 4:1037-1044.

Salmond, G. P. C., Bycroft, B. W., Stewart, G. S. A. B., and Williams, P. 1995. The bacterial 'enigma': Cracking the code of cell-cell communication. Mol. Microbiol. 16:615-624.

Salmond, G. P. C., and Reeves, P. J. 1993. Membrane traffic wardens and protein secretion in gram-negative bacteria. Trends Biochem. Sci. 18:7-12.

Sambrook, J., Fritsch, E. F., and Maniatis, T. A. 1989. Molecular Cloning: A Laboratory Manual. 2nd ed. Cold Spring Harbor Laboratory, Cold Spring Harbor, NY.

Sanger, F., Nicklen, S., and Coulson, A. R. 1977. DNA-sequencing with chain-terminating inhibitors. Proc. Natl. Acad. Sci. USA 74:54635467.

Shadel, G. S., Young, R., and Baldwin, T. O. 1990. Use of regulated cell lysis in a lethal genetic selection in Escherichia coli: Identification of the autoinducer-binding region of the LuxR protein from Vibrio fischeri ATCC 7744. J. Bacteriol. 172:3980-3987.

Slock, J., vanRiet, D., Kolibachuk, D., and Greenberg, E. P. 1990. Critical regions of the Vibrio fischeri LuxR protein defined by mutational analysis. J. Bacteriol. 172:3974-3979.

Swift, S., Throup, J. P., Williams, P., Salmond, G. P. C., and Stewart, G. S. A. B. 1996. Quorum sensing: A population-density component in the determination of bacterial phenotype. Trends Biochem. Sci. 21: 214-219.

Swift, S., Winson, M. K., Chan, P. F., Bainton, N. J., Birdsall, M. Reeves, P. J., Rees, C. E. D., Chhabra, S. R., Hill, P. J., Throup, J. P., Bycroft, B. W., Salmond, G. P. C., Williams, P., and Stewart, G. S. A. B. 1993. A novel strategy for the isolation of luxI homologues: Evidence for the widespread distribution of a LuxR:LuxI superfamily in enteric bacteria. Mol. Microbiol. 10:511-520.

Tabor, S. 1990. Expression using the T7 RNA polymerase/promoter system. Pages 16.2.1-16.2.11 in: Current Protocols in Molecular Biology. F. A. Ausubel, R. E. Brent, D. D. Kingston, J. G. Moore, J. G. Seidman, J. A. Smith, and K. Struhl, eds. Greene Publishing and Wiley Interscience, New York.

Tabor, S., and Richardsson, C. C. 1985. A bacteriophage T7 RNA polymerase/promoter system for controlled exclusive expression of specific genes. Proc. Natl. Acad. Sci. USA. 82:1074-1078.

Thomson, N. R., Cox, A., Bycroft, B. W., Stewart, G. S. A. B., Williams, P., and Salmond, G. P. C. 1997. The Rap and Hor proteins of Erwinia, Serratia and Yersinia: A novel subgroup in a growing superfamily of proteins regulating diverse physiological processes in bacterial pathogens. Mol. Microbiol. 26:531-544.

Thomson, N. R., Nasser, W., McGowan, S., Sebaihia, M., and Salmond, G. P. C. 1999. Erwinia carotovora has two KdgR-like proteins belonging to the IclR family of transcriptional regulators: Identification and characterisation of the RexZ activator and the KdgR repressor of pathogenesis. Microbiology 145:1531-1545.

Throup, J. P., Camara, M., Briggs, G. S., Winson, M. K., Chhabra, S. R., Bycroft, B. W., Williams, P., and Stewart, G. S. A. B. 1995. Characterization of the yenI/yenR locus from Yersinia enterocolitica mediating the synthesis of two $N$-acylhomoserine lactone signal molecules. Mol. Microbiol. 17:345-356.

Vidal, S., Eriksson, A. R. B., Montesano, M., Denecke, J., and Palva, E. T. 1998. Cell wall-degrading enzymes from Erwinia carotovora cooperate in the salicylic acid-independent induction of a plant defense response. Mol. Plant-Microbe Interact. 11:23-32.

von Bodman, S. B., and Farrand, S. K. 1995. Capsular polysaccharide biosynthesis and pathogenicity in Erwinia stewartii require induction by an $\mathrm{N}$-acylhomoserine lactone autoinducer. J. Bacteriol. 177:50005008 .

von Bodman, S. B., Majerczak, D. R., and Coplin, D. L. 1998. A negative regulator mediates quorum-sensing control of exopolysaccharide production in Pantoea stewartii subsp. stewartii. Proc. Natl. Acad. Sci. USA 95:7687-7692.

Wilson, G. G., Young, K. K. Y., Edlin, G. J., and Konigsberg, W. 1979. High-frequency generalised transduction by bacteriophage T4. Nature 280:80-82.

Wilson, K. J. 1996. Molecular Microbiology Ecology Manual. Kluwer Academic Publishers, Dordrecht, The Netherlands. chap. 6.1.5, pp. 125. 